\title{
INCIDÊNCIA DE SOROCONVERSÃO PARA O VÍRUS DA HEPATITE C APÓS A IMPLEMENTAÇÃO DE PROGRAMA DE PREVENÇÃO E CONTROLE EM UNIDADE DE HEMODIÁLISE*
}

\author{
Fabiana Alvares da Silva Lazzarini** \\ Denise de Andrade*** \\ Lidia Aparecida Rossi*** \\ Ana Emília Pace Ferraz***
}

\begin{abstract}
LAZZARINI, F.A.da S.; ANDRADE, D. de; ROSSI, L.A.; FERRAZ, A.E.P. Indicência de soroconversão para o vírus da hepatite $\mathrm{C}$ após a implementação de programa de prevenção e controle em unidade de hemodiálise. Rev.latinoam.enfermagem, Ribeirão Preto, v. 8, n. 5, p. 7-12, outubro 2000.
\end{abstract}

Os objetivos deste estudo foram relatar a incidência de hepatite C, e as medidas de prevenção e controle adotadas em unidade de hemodiálise. Trata-se de estudo coorte prospectivo realizado em pacientes atendidos no período de setembro/1996 à dezembro/1998 em unidade de hemodiálise. Os atendimentos realizados no periodo de setembro/1996 à dezembro/1996 foram considerados grupo controle e os realizados no periodo de janeiro/1997 à dezembro/1998 grupo de intervenção. No periodo em que foram atendidos os pacientes do grupo controle, as rotinas da unidade estavam organizadas com base na Portaria 2042, que versa sobre funcionamento de serviços de terapia renal. No periodo subseqüente foram implementadas medidas complementares, observando-se redução do número de soroconversão para o vírus da hepatite C.

UNITERMOS: hepatite C, hemodiálise, enfermagem

\section{INTRODUÇÃO}

A hemodiálise é uma modalidade terapêutica utilizada principalmente para tratamento da uremia na insuficiência renal. No Brasil, é responsável pela sobrevida de aproximadamente 34.000 pessoas. Os pacientes urêmicos em programa de hemodiálise estão freqüentemente expostos às infecções bacterianas e virais. Dentre as infecções virais a mais freqüente é a hepatite (FERRABOLI \& ABENSUR, 1998).

A maioria das hepatites, que ocorre entre pacientes em tratamento por hemodiálise, não é causada nem pelo vírus da hepatite do tipo A (HAV), nem pelo vírus da hepatite do tipo $\mathrm{B}$ (HBV), mas sim pelo vírus da hepatite do tipo C (HCV) (SALOM, 1997), cuja a clonagem de antígenos específicos foi possível no final da década de 80, frente aos avanços da biologia molecular (SOUZA \& WENDEL, 1997).

Atualmente, a infecção pelo vírus do tipo C é considerada a principal causa de doença hepática crônica nos pacientes em diálise e transplantados renais, aproximadamente $85 \%$ dos infectados evoluem para cronicidade e a cirrose é a terceira causa de óbito nos transplantados renais a longo prazo (SEEFF, 1997).

Embora a taxa de hepatite do tipo $\mathrm{C}$ pós transfusão varie distintamente em diferentes partes do mundo, essa doença pode ser considerada endêmica (BARBARA, 1992). A transmissão do HCV é predominantemente por via parenteral e também pode ser disseminada por via sexual (ALTER et al., 1990). Os pacientes em diálise estão constantemente expostos a contaminação em função dos procedimentos invasivos a que são submetidos e da exposição a outros pacientes infectados (MOYER \& ALTER, 1994). Segundo essas autoras, quanto maior o tempo de diálise, maior a prevalência de positividade para o vírus da hepatite do tipo C. O aumento da prevalência varia de uma média de $12 \%$ de pacientes em tratamento dialítico por menos de 5 anos para $37 \%$ de pacientes em tratamento por mais de 5 anos. Segundo MOYER \& ALTER (1994), a

\footnotetext{
* Trabalho apresentado ao Curso de Especialização de Enfermagem em Nefrologia da Escola de Enfermagem de Ribeirão Preto da Universidade de São Paulo

** Enfermeira Chefe de uma Unidade de Diálise Peritonial, Hemodiálise e Transplante Renal. Aluna do Curso de Especialização de Enfermagem em Nefrologia da Escola de Enfermagem de Ribeirão Preto da Universidade de São Paulo

*** Professoras Doutoras do Departamento de Enfermagem Geral e Especializada da Escola de Enfermagem de Ribeirão Preto da Universidade de São Paulo
} 
prevalência da hepatite do tipo $\mathrm{C}$ em unidades de hemodiálise está mais associada ao tempo de diálise do que à transfusões de hemoderivados, o que para essas autoras, sugere que a transmissão ocorre de um paciente para outro possivelmente por causa de falhas no controle de infecção. Esses dados são corroborados pelo estudo de PETROSILLO et al. (1993) que identificaram uma maior prevalência de $\mathrm{HCV}$ positivo em pacientes em diálise acima de 5 anos.

Devido a deficiência imunológica causada pela uremia e a dificuldade para eliminação dos vírus, os pacientes em hemodiálise se tornam reservatórios, participando como elementos importantes na cadeia de transmissão para outros pacientes, funcionários e até para a própria família (DEGOS \& JUNGERS, 1995).

Um estudo realizado em uma unidade de hemodiálise, demonstrou a diminuição da incidência do $\mathrm{HCV}$ decorrente da diminuição do número de transfusões sangüíneas e de um efetivo controle de infecção hospitalar com ênfase nesse patógeno. A transmissão do HCV por produtos de transfusão sangüínea e pela troca de agulhas entre usuários de drogas tem sido demonstrada, assim como, a transmissão horizontal por via sexual, exposição no lar e a vertical mãe para feto (PEREIRA, 1996).

Desta forma, a contaminação dos pacientes dialisados pelo vírus HCV poderá se dar quando não são dispensados cuidados básicos e/ou específicos durante $o$ contato com pacientes HCV positivos e HCV negativos, através do manuseio inadequado na instalação das máquinas de hemodiálise, da transfusão de hemoderivados e do uso comum de diversos artigos médicos hospitalares.

A instalação de medidas de prevenção e controle, visando reduzir ou anular a possibilidade da transmissão do HCV entre pacientes dialisados, é recurso fundamental para o controle de qualidade dos serviços de hemodiálise.

$\mathrm{Na}$ Unidade de Hemodiálise onde realizamos este estudo, constatamos que, apesar de as rotinas estarem organizadas, de acordo com as recomendações expressas pela Portaria 2042 que regulamenta o funcionamento dos serviços de terapia renal (BRASIL, 1996), houve um aumento significativo do número de soroconversões para hepatite do tipo C a partir do segundo semestre de 1996. Preocupados com essa situação, passamos a nos questionar sobre as medidas que poderiam ser utilizadas visando a garantia do cumprimento das rotinas estabelecidas e assegurar a prevenção e o controle de infecções nesta unidade. Assim, decidimos realizar este estudo que teve como objetivo verificar a incidência de casos de soroconversão positiva para hepatite do tipo C, antes e após a implementação de um Programa de Prevenção e Controle, em uma unidade de hemodiálise do interior do Estado de São Paulo, SP.

\section{METODOLOGIA}

O presente estudo foi desenvolvido em uma Unidade de Hemodiálise do interior do Estado de São Paulo após a obtenção do consentimento do responsável pela instituição. Esta unidade tem capacidade para atender 100 pacientes em programa de hemodiálise e atualmente atende 74 pacientes. A equipe de saúde que atua no local é composta por dois médicos nefrologistas, duas enfermeiras, sete técnicos e quatro auxiliares de enfermagem. Possui 20 máquinas para hemodiálise tipo proporção, das quais 18 operam diariamente em dois turnos e duas ficam de reserva.

Trata-se de um estudo tipo coorte prospectivo realizado em pacientes atendidos no programa de hemodiálise no período de setembro de 1996 à dezembro de 1998. Como afirma SILVA (1998), nesse tipo de estudo, a observação é realizada na direção da exposição dos indivíduos (sem e com a doença) ao fator associado, "para posterior detecção e comparação da incidência entre os dois grupos de casos". Com base nessa concepção, os pacientes atendidos no período de setembro de 1996 à dezembro de 1996 foram considerados como grupo controle e os pacientes atendidos no período de janeiro de 1997 à dezembro de 1998 como grupo de intervenção.

No período em que os pacientes do grupo controle foram atendidos, as rotinas da unidade estavam organizadas com base na Portaria 2042 (BRASIL, 1996). No período subseqüente, foram implementadas medidas complementares à essa portaria; neste estudo, descritas em conjunto com a apresentação dos resultados.

Nos dois períodos, foi verificada a incidência de soro conversão para hepatite $\mathrm{C}$ através da monitorização mensal laboratorial de todos os pacientes atendidos por meio da TGP (Transamisanase Glutâmico Pirúvica) e teste para sorologia anti-HCV Elisa de terceira geração.

\section{RESULTADOS E DISCUSSÃO}

Foram atendidos 38 pacientes e registradas sete soroconversões para HCV no período de setembro de 1996 à dezembro de 1996, considerado como grupo controle. Após esse período, mediante o aumento do número de atendimentos (casos novos) foi observado, também, um aumento do número de casos de soroconversão positiva para o vírus de hepatite $\mathrm{C}$.

Nesse período, foram utilizadas as mesmas salas para dialisar pacientes com anti-HCV positivo e negativo, separando-os apenas por turno. Os pacientes foram dialisados nas mesmas máquinas de hemodiálise, após terem sido submetidas a processo de desinfecção com hipoclorito de sódio a $10 \%$, com exposição ao produto 
por 30 minutos. O carrinho de curativo era comum para todos os pacientes, anti-HCV positivos e negativos, sendo observados, rigorosamente, todos os cuidados de assepsia a fim de impedir a infecção cruzada. Quanto à sala de reuso, local destinado ao reprocessamento de material, apesar de ser única, continha duas bancadas separadas para receber material dos pacientes portadores ou não do vírus da hepatite $\mathrm{C}$. Tais normas e rotinas de trabalho foram mantidas até o momento em que houve a confirmação do primeiro caso de hepatite do tipo C, ou seja, em dezembro de 1996.

Neste período, o isolamento dos pacientes contaminados foi dificultado uma vez que a janela imunológica pode ser de até seis meses (FERRAZ et al., 1995). Segundo HOLLINGER (1987), os testes para detecção de anti-HCV por meio da sorologia mostram um período aproximado de incubação de até seis meses (janela imunológica). SHIMOTOHNO \& FEINSTONE (1997) relatam que os serviços de diálise necessitam de tecnologia avançada para detectar precocemente anticorpos anti-HCV, uma vez que existem testes tidos como limitados.

As medidas iniciais de intervenção foram implementadas após reunião com todos os profissionais atuantes na unidade, na qual foram adotadas estratégias de prevenção e controle da transmissão do HCV na referida unidade de diálise e estão descritas a seguir.

\section{Treinamento de pessoal}

- Educação continuada, com ênfase na atuação dos profissionais quanto às medidas de prevenção e controle dentre as quais citamos as "precauções padrão" (universais), bem como, a rigorosa desinfecção das máquinas e de superfícies conforme a Portaria 2042 do Ministério da Saúde (BRASIL, 1996), já mencionada anteriormente.

- Supervisão constante dos profissionais durante a realização de todas as atividades.

\section{Revisão de normas e rotinas}

- Manutenção da mesma sala de hemodiálise, com isolamento de pacientes apenas por turno, invertendo-se a ordem de realização das sessões de hemodiálise dos pacientes HCV negativos e HCV positivos, ou seja, os pacientes $\mathrm{HCV}$ negativos dialisavam no primeiro turno e os pacientes HCV positivos no segundo turno após desinfecção das máquinas. Essa estratégia foi utilizada com o objetivo de garantir a segurança, aumentando o tempo de inatividade das máquinas entre a utilização em pacientes HCV positivos e em HCV negativos.

- Manutenção da sala de reprocessamento de equipamentos e artigos médico - hospitalares (reuso), com bancadas exclusivas para pacientes $\mathrm{HCV}$ positivos e para negativos.

- Redução ao máximo das transfusões sangüíneas, com o uso de ferro endovenoso e eritropoetina recombinante, a critério da equipe médica (FERRABOLI \& ABENSUR, 1998).

- Manutenção da monitorização laboratorial mensal de todos os pacientes atendidos.

Essas medidas complementares foram implementadas com o objetivo de contribuir para a garantia do cumprimento das rotinas estabelecidas na Portaria 2042 (BRASIL, 1996).

Apesar das mudanças implementadas, em dezembro de 1997, o número de casos de hepatite do tipo $\mathrm{C}$ aumentou. Nesse ano, constatou-se a viragem sorológica de 22 dos 60 pacientes que estavam sendo submetidos a hemodiálise. Diante do ocorrido, foi decidido avaliar novamente a situação com a finalidade de detectar falhas nas normas e rotinas preestabelecidas para que fosse possível estabelecer as intervenções compatíveis com a situação.

Segundo BARROS et al. (1994); JADOUL et al. (1997) e CRUZ et al. (1998) a redução da contaminação por HCV mediante a implementação de "precauções universais" já é conhecida. Dentre os fatores direta e indiretamente relacionados à cadeia de transmissão do vírus da hepatite $\mathrm{C}$ destacam-se: administração de múltiplas doses de heparina entre pacientes com e sem HCV sem a troca de luvas pelos profissionais ao cuidar dos pacientes; falha na limpeza e desinfecção de instrumentos e superfícies manipulados rotineiramente; utilização das mesmas máquinas para pacientes $\mathrm{HCV}$ positivos e negativos, utilização dos mesmos artigos para todos os pacientes sem desinfecção prévia; utilização indiscriminada das salas de reuso e de hemodiálise tanto para os pacientes $\mathrm{HCV}$ positivos quanto para os negativos, sem as devidas precauções (ALTER, 1997). Tais fatores, também, foram identificados no serviço a partir da nova avaliação realizada.

Frente ao exposto, foram deliberadas algumas intervenções com o auxílio de uma enfermeira experiente em medidas de controle das infecções hospitalares. A meta foi reduzir a zero a contaminação pelo HCV. Teve início assim o período denominado de intervenção, com uma nova programação educativa sobre prevenção e controle de infecções em unidade de hemodiálise. Em seguida foi adotada medida de fiscalização efetiva de todas as atividades exercidas nas salas de reuso e de hemodiálise com ênfase nos procedimentos para precauções padrão (lavagem de mãos, uso de luvas, aventais, dentre outros equipamentos de proteção individual).

Foram revistas e atualizadas todas as normas e rotinas de enfermagem. Foi observado também o contato 
direto ou indireto ou ambos entre profissionais e pacientes levando-se em conta os seguintes aspectos:

- reavaliação dos recursos materiais (equipamentos e artigos médico-hospitalares) com ênfase nas atividades de processamento e reprocessamento;

- reavaliação dos recursos humanos (equipes médica e de enfermagem) no desempenho de suas atividades.

A partir dessa nova avaliação, foram organizadas salas de hemodiálise separadas para pacientes portadores de hepatite dos tipos $\mathrm{C}$ e $\mathrm{B}$ e pacientes indeterminados (iniciando hemodiálise, sem sorologia definida), e pacientes com todas as sorologias negativas, além do reforço das "precauções universais" orientadas pelo Center Disease of Control (CENTER DISEASE OF CONTROL AND PREVENTION, 1990) e implementadas através de educação continuada em serviço dos funcionários da unidade.

A transmissão de HCV tem sido relacionada à proximidade física. PEREIRA (1996) relatou a redução desta transmissão utilizando sala exclusiva para pacientes $\mathrm{HCV}$ positivos. Esse mesmo autor mostrou a redução da incidência de HCV utilizando máquinas de diálise exclusivas para pacientes HCV positivos e a utilização de salas de reuso separadas para esses mesmos pacientes.

No entanto, SALOM (1997) afirma que os pacientes HCV positivos não necessitam de sala de hemodiálise isolada e podem participar do programa de reuso de dialisadores, desde que os procedimentos sejam realizados com base nas aplicações das precauções universais, ou seja, através do uso de barreiras básicas (lavagem das mãos, uso de luvas, aventais, máscaras, óculos, etc.).

A principal causa da infecção cruzada por $\mathrm{HCV}$ descrita na literatura é o não cumprimento das precauções universais e a falta de padronização rigorosa que atenda as especificidades de cada situação (CRUZ et al., 1998).

Surtos de hepatite $\mathrm{C}$ em unidades de hemodiálise tem sido associados com falhas humanas como usar seringas com múltiplas doses de heparina entre pacientes diferentes e falhas em trocar luvas ao manipular pacientes, principalmente ao comprimir os sítios de punção (ALTER, 1997). Além do controle dessas atividades, também são necessárias limpeza rigorosa e desinfecção de todos os instrumentos e superfícies.

Assim, a separação das salas de hemodiálise para pacientes HCV positivos e negativos pode ser uma medida complementar a Portaria 2042 (BRASIL, 1996) para aumentar a segurança considerando que podem ocorrer falhas humanas.

Em dezembro de 1998, considerando que o intervalo de soroconversão para o $\mathrm{HCV}$ varia de 2 a 6 meses após a contaminação (FERRAZ et al., 1995), os resultados deste estudo finalmente puderam ser observados com a viragem sorológica de sete pacientes dos 64 que estavam sendo submetidos à hemodiálise. Esses novos casos foram confirmados em março de 1998, quando após esta data até dezembro de 1998 não ocorreram outros casos de contaminação pelo HCV. Assim, após a implantação efetiva das medidas de prevenção e controle foi possível, após um período de um ano, verificar uma redução significativa do número de casos de contaminação pelo $\mathrm{HCV}$ em nosso serviço de hemodiálise (Tabela 1), em ambos períodos considerados.

Acreditamos que, a aplicação adequada das precauções padrão e a separação dos pacientes portadores de HCV colaboraram para a diminuição da incidência observada em nosso meio.

Tabela 1 - Distribuição das notificações de hepatite por vírus C no período de 1997 a 1998

\begin{tabular}{ccc}
\hline Mês/Ano & $\begin{array}{c}N^{\mathbf{D}} \text { total de } \\
\text { pacientes em } \\
\text { hemodiálise }\end{array}$ & $\begin{array}{c}\mathrm{N}^{\mathrm{D}} \text { de soroconversóes } \\
\text { para HCV positivos } \\
\mathbf{0}\end{array}$ \\
\hline $\begin{array}{c}\text { Janeiro à Dezembro } \\
1997\end{array}$ & 60 & $22(36,6 \%)$ \\
\hline $\begin{array}{c}\text { Janeiro à Dezembro } \\
1998\end{array}$ & 64 & $7(10,9 \%)$ \\
\hline
\end{tabular}

Através da aplicação do teste para diferença entre duas proporções com um nível de significância $\alpha=0,05$, foi verificado uma diminuição significativa do número de casos de soroconversão positiva entre os dois períodos estudados $(\mathrm{z}=3,44, \mathrm{p}<0,05)$.

É notória a redução do número de soroconversões para HCV no período de 1997 a 1998, ou seja, 22 para 7 casos. Os resultados obtidos neste estudo permitem verificar a redução do número de casos de soro conversão através de implementação de medidas de prevenção e controle de HCV. Assim, as medidas complementares adotadas nesta unidade podem ter contribuído para a garantia do cumprimento das rotinas estabelecidas com base nas recomendações da Portaria 2042 (BRASIL, 1996).

Mesmo tendo consciência de que tais medidas poderão não ser totalmente aplicáveis em muitas unidades de hemodiálise no Brasil, certamente podem ser úteis como referência para outros serviços e outros estudos.

\section{CONSIDERAÇÕES FINAIS}

Há controvérsias quanto à necessidade de salas de hemodiálise separadas para pacientes HCV positivos e negativos, entretanto, neste estudo, considera-se 
possível que a separação das salas de hemodiálise e de reuso tenha sido fator determinante para a redução significativa do número de casos de hepatite $\mathrm{C}$.

As unidades de hemodiálise dependem do avanço da tecnologia e estão em constante mudança, exigindo a atualização permanente da equipe para o cumprimento de normas que visam a biossegurança dos pacientes e profissionais. Além disso, as pesquisas científicas nessa temática são fundamentais.

Entendemos que as medidas de intervenção para prevenção e controle da hepatite do tipo $\mathrm{C}$, adotadas nesta Unidade, foram eficientes para redução da incidência das infecções. Por outro lado, analisando aquelas unidades de hemodiálise cuja estrutura não permite o isolamento de pacientes, julgamos que a utilização rigorosa e adequada dos anti-sépticos, desinfetantes e esterilizantes, processamento e reprocessamento de artigos, superfícies e precauções padrão poderá auxiliar na prevenção e controle de contaminação não só pelo $\mathrm{HCV}$, mas, também por outros patógenos.

Os resultados obtidos neste estudo estão associados não só ao isolamento de pacientes, mas também, ao cumprimento das recomendações supra citada, sugerindo que tais medidas atuaram efetivamente na redução do HCV.

\section{INCIDENCE OF THE HEPATITIS C VIRUS AFTER THE IMPLEMENTATION OF A PREVENTION AND CONTROL PROGRAM AT AN HEMODIALYSIS UNIT}

This study aimed at reporting the incidence of the hepatitis $C$ virus as well as the prevention and control measures adopted in an hemodialysis unit. It is a prospective study developed with patients attended from September 1996 to December 1998 in an hemodialysis unit. The consultations from September 1996 to December 1996 were considered the control group and the ones from January 1997 to December 1998 the intervention group. Regarding the period of the control group, the routine of the unit was organized based on the regulation 2042 that systematizes the services of renal therapy. In the subsequent period, complementary measures were implemented. From 1997 to 1998, authors observed the reduction in the number of cases of hepatitis $C$.

KEY WORDS: hemodialysis unit, hepatitis C virus, nursing

\section{INCIDENCIA DE SEROCONVERSIÓN POSITIVA PARA EL VIRUS DE LA HEPATITIS C DESPUÉS DE LA IMPLEMENTACIÓN DE UN PROGRAMA DE PREVENCIÓN Y CONTROL EN UNA UNIDAD DE HEMODIÁLISIS}

Los objetivos de este estudio fueron relatar la incidencia de hepatitis tipo C y las medidas de prevención y control adoptadas en una unidad de hemodiálisis. Se trata de un estudio prospectivo realizado con pacientes que fueron atendidos en el periodo de septiembre/1996 a diciembre/1998. Las atenciones realizadas durante el periodo de septiembre/1996 a diciembrel 1996 fueron consideradas grupo control y las realizadas durante el periodo de enero/1997 a diciembre/1998 grupo de intervención. Durante el primer periodo las rutinas de la unidad fueron organizadas con base en la ley 2042 que reglamenta el funcionamiento de los servicios de terapia renal y para el segundo periodo se implementaron algunas medidas complementarias. De 1997 a 1998 las autoras observaron que disminuyó el número de casos de seroconversión para el virus de la Hepatitis tipo C.

TÉRMINOS CLAVES: unidad de hemodiálisis, hepatitis tipo C, enfermería

\section{REFERÊNCIAS BIBLIOGRÁFICAS}

01. ALTER, M.J. Epidemiology of hepatitis C. Hepatology, v. 26, n. 3, p. 62-5, 1997.

02. ALTER, M.J. et al. Risk Factors for acute non-A, non-B hepatitis in the United States and association with hepatitis $\mathrm{C}$ virus infection. JAMA, v. 264, p. 231-5, 1990.

03. BARBARA, J.A.J. Hepatitis $\mathrm{C}$ and blood transfusion. Curr. Opin. Infect. Dis., v. 5, p. 536 -41, 1992.

04. BARROS, E. et al. Nefrologia: rotinas, diagnóstico e tratamento. Porto Alegre: Artes Médicas Sul, 1994.
05. BRASIL. Leis etc. Portaria n ${ }^{\circ} 2042$ de 11 de outubro de 1996. Dispõe sobre o Regulamento técnico para funcionamento dos serviços de terapia renal substitutiva e as normas para cadastramento desses estabelecimentos junto ao Sistema Único de Saúde. Diário Oficial da União, Brasilia, 11 de out. de 1996.

06. CENTER FOR DISEASE CONTROL AND PREVENTION - Protection against viral hepatits. Recomendations of the immnization. Practices Adivsory committee. MMWR, v. 39 (RR-2), p. 1-27, 1990. 
07. CRUZ, J.; BARROS, R.T.; CRUZ, H.M.M. Atualidades em Nefrologia. São Paulo: Sarvier, 1998.

08. DEGOS, F.; JUNGERS, P. Viral infections in dialysis patients dialysis associated hepatitis. In: JACOBS, C. et al. Replacement of renal function by dialysis. 4. ed. New York: Reuwer Academic Publishers, 1995. p. 1133-59.

09. FERRABOLI, R.; ABENSUR, H. Infecções pelo vírus $C$ em unidade de Diálise. São Paulo: Unidade de Diálise do Serviço de Nefrologia do Hospital das Clínicas da Faculdade de Medicina da Universidade de São Paulo, 1998. / Mimeografado/.

10. FERRAZ, M.L.G.; SILVA, A. E. B.; LOPEZ NETO, E.P.A. Como diagnosticar e tratar hepatites virais. Rev. Bras. Med., v. 51, p. 86-93, 1995. (Edição Especial).

11. HOLLINGER, B.F. Serologic evaluation of viral hepatitis. Hosp. Pract., v. 22, n. 2, p. 101-14, 1987.

12. JADOUL, M.; CHANTAL, C.; CHARLES, V.Y.S. Universal precautions prevent hepatitis $C$ virus transmission: A 54 month follow - up of the Belgian multicenter study. Kidney Int., v. 53, p. 1022-5, 1997.
13. MOYER, L.A.; ALTER, M.J. Hepatitis C virus in the hemodialysis setting: a review with recommendations for control. Semin. Dial., v. 7 , p. 124-7, 1994.

14. PEREIRA, B.J.G. Hepatitis C by dialysis. Boston: Division of Nephrology, New England Medical Center, 1996.

15. PETROSILLO, N.; VINCENZO, P.; GIUSEPPE, I. Prevalence of human imnunodeficiency virus, hepatitis $\mathrm{B}$ and hepatitis $\mathrm{C}$ among dialysis patitents. Nephron, v. 64, p. 636-9, 1993.

16. SALOM, R. Centro de Hemodiálise. In: COUTO, R.C. et al. Infecção hospitalar: epidemiologia e controle. São Paulo: MEDSI, 1997. Cap. 31, p. 443-53.

17. SEEFF, L.B. Natural history of hepatitis C. Hepatology, v. 26, n. 3, p. 21-8, 1997.

18. SHIMOTOHNO, K.; FEINSTONE, S. M. Hepatitis $\mathrm{C}$ virus and hepatitis G virus. In: RCHMAN, D.D.; WHITLEY, R.J.; HAYDEN, F.G. (Eds.). Clinical virology. New York: Churchil Churchill Livingstone, 1997. p. 1187-215.

19. SILVA, N.N. Amostragem probabilística: um curso introdutório. São Paulo: Edusp, 1998.

20. SOUZA DIAS, M.B. de; WENDEL, S. Infecções transmitidas pelo sangue. In: RODRIGUES, E.A.C. et al. Infecções hospitalares: prevenção e controle. São Paulo: Sarvier, 1997. p. 305-11. 